\section{El marco regulatorio del control político sobre el Órgano Ejecutivo (L) ${ }^{1}$}

\author{
Ruth Eleonora López Alfaro² \\ Ana Gabriela Santos Guardado ${ }^{3}$ \\ Hugo Álvaro Rivas Tenorio ${ }^{4}$
}

Palabras clave:

rendición de cuentas, marco regulatorio, regulación del control político.

\begin{abstract}
Resumen
El presente artículo aborda el aspecto normativo de algunas instituciones que ejercen control político sobre el órgano ejecutivo, a fin de caracterizar la letra "L", que forma parte de los elementos de la rendición de cuentas horizontal. Para ello se describe el marco regulatorio de las prácticas de algunas instituciones que tienen facultades de control político sobre el Ejecutivo y se esbozan elementos del ordenamiento jurídico que precisan mejorar, a fin de tener una rendición de cuentas efectiva.
\end{abstract}

\section{Introducción}

La rendición de cuentas $(\mathrm{RdC})$, según Artiga-González et al. (2008), es "un sistema de prácticas institucionales a través de las cuales los gobernantes y funcionarios públicos son evaluados, siguiendo diversos criterios, $y$ de cuyo resultado se derivan premios 0 sanciones para los mismos" (p. 4). De ahí que puedan extraerse cuatro elementos o partes que Lindberg (2009) ha considerado como la médula de la RdC: (1) el agente, es decir, el sujeto del órgano ejecutivo que rinde cuentas; (2) un dominio o ámbito sobre lo que se rinde cuentas; (3) el principal, a quien el agente le rinde cuentas, $y$, finalmente, (4) el derecho, tema principal de este artículo (p. 8).

$1 \quad$ Este artículo es un avance de la investigación: "El ejercicio del control político institucional sobre el Órgano Ejecutivo en El Salvador, 1999-2019", que llevan a cabo los departamentos de Sociología y Ciencias Políticas, y Ciencias Jurídicas de la Universidad Centroamericana José Simeón Cañas (UCA), con financiamiento del Fondo de Investigación UCA.

2 Profesora del departamento de Ciencias Jurídicas de la UCA.

3 Profesora e investigadora del departamento de Ciencias Jurídicas de la UCA.

4 Estudiante de la Licenciatura en Ciencias Jurídicas de la UCA, contratado como investigador asociado. 
El derecho se simboliza con la "L", letra que deriva del inglés Law, para expresar la dimensión normativa de la rendición de cuentas. Así, dentro del núcleo básico, se encuentra el derecho (L) del principal (P) de requerir del agente $(\mathrm{A})$ información y explicación/justificación de sus decisiones y acciones respecto al dominio (D) y el derecho (L) de $\mathrm{P}$ de sancionar a A si este no provee información y explicación/justificación satisfactoria sobre las decisiones respecto a $\mathrm{D}$.

En El Salvador, existen ciertas instituciones que tienen facultades de control político sobre el Ejecutivo, entendido este como la presidencia, la vicepresidencia y los diferentes ministerios, entidades descentralizadas y empresas públicas. La Asamblea Legislativa, la Sala de lo Constitucional y la Corte de Cuentas son algunas instancias que realizan prácticas institucionales de control interorgánico sobre el Ejecutivo y cuyo marco normativo se analizará, a fin de evidenciar aquellos elementos, desde un punto de vista jurídico, que influyen para que el sistema de rendición de cuentas opere correctamente.

Para ello, en los primeros apartados, se abordarán líneas generales sobre la regulación de control. A continuación, se explican los órganos y las respectivas prácticas de control que realizan, de acuerdo con la finalidad de este artículo. Finalmente, se abordan algunos aspectos del marco regulatorio que tiene deficiencias que debiesen ser superadas, a fin de contar con una rendición de cuentas efectiva.

El marco regulatorio no es todo lo que influye en el sistema de rendición de cuentas, pero sienta las bases para que sobre esto actúen los demás actores. Es la parte objetiva de la rendición de cuentas, en el sentido de que las directrices han sido dadas $y$, en principio, lo que se presume es que deben ser acatadas.

Sin embargo, antinomias en la ley, pero especialmente los vacíos, debilitan este pilar fundamental de la RdC.

\section{Sobre la regulación del control}

El derecho, palabra polisémica por excelencia, en una primera acepción, hace referencia a las facultades que posee una parte y las correspondientes obligaciones para la otra, así como la consecuencia de su inobservancia. En el marco de la rendición de cuentas, Schedler (2011) utiliza dos términos para ambas situaciones: answerability y enforcement.

Rodríguez Padilla et al. (2011) identifica en la answerability dos grandes momentos de la rendición de cuentas: la "publicación de la información (relacionada con la actuación de los servidores públicos mediante la generación de indicadores y datos de calidad)" $y$, con posterioridad, "la justificación (estos servidores públicos deben basar su actuación en las atribuciones que la ley establece para los cargos que ocupan)" (p. 11). Para otros autores como Peixoto (2013), este primer momento del answerability es de tal relevancia que lo identifica como la parte fundamental del proceso de rendición de cuentas, afirmando que "la transparencia puede permitir la rendición de cuentas solo cuando se cumple la condición de publicidad" (p. 204), lo que, según dicho autor, se concreta a través de cuatro eventos mínimos: divulgación de la información, recepción de esta por los destinatarios, capacidad del público de procesarla y reaccionar, y respuesta de los funcionarios a las reacciones, así como su sanción por medios institucionales ante incumplimientos. Este último evento es el enforcement, como atribución del $\mathrm{P}$ para "sancionar a políticos $y$ funcionarios en caso de que hayan violado sus deberes públicos" (Schedler, 2011), con el fin de, como apunta Fagbadedbo (2019), "rectificar el fallo de gobernanza mediante la disuasión" (p. 2) o mediante sanciones políticas, administrativas, civiles o fiscales (incluyendo las consecuencias penales), como señala Payne et al. (pp. 132-133).

En esencia, se trata de una relación entre A y $\mathrm{P}$, donde debería darse un constante intercambio de información relativa a las actividades que aquellos llevan a cabo y de 
la existencia de consecuencias tanto por la falta de retroalimentación como por la falta de cumplimiento de las obligaciones en la RdC.

En el contexto salvadoreño, en el proceso de inconstitucionalidad 6-2020 Ac, del 30 de octubre de 2020, la Sala de lo Constitucional se pronunció sobre el deber de justificar los actos y decisiones que implican el ejercicio del poder público. En esa sentencia, la Sala señaló que "la única forma en la que la ciudadanía puede controlar la sujeción de los poderes públicos a la Constitución, leyes y demás fuentes de derecho es mediante la justificación, motivación y fundamentación que estos hagan de los actos que realicen en ejercicio de sus competencias", permitiendo con ello eliminar visos de arbitrariedad o voluntarismo en la toma de decisiones $y$, por ende, espacios corruptibles. De esta manera, la aplicación del derecho al recibir la publicidad necesaria reduce las circunstancias en las que puede actuar un agente corruptor.

De ahí la relevancia de delimitar no solo las acciones de servidores públicos, según las competencias establecidas a cada uno en los cuerpos normativos correspondientes, sino de las consecuencias legales ante la inobservancia de los marcos normativos. Esto también es parte del derecho del que deriva su segundo carácter: el cuerpo normativo que estandariza las obligaciones de los servidores públicos según el dominio en el que se desempeñan y que rigen las prácticas institucionales de $\mathrm{RdC}$.

Para que exista una efectiva accountability, como dice Velásquez Leal e Insausti (2014), que revele "la existencia de las dimensiones de información, explicación, responsabilidad y sanción" necesita de condiciones como "la disponibilidad de un marco normativo adecuado a este propósito y el cumplimiento con esas normas por parte de los funcionarios y/o servidores públicos" (p. 12). Así, aparejado al marco regulatorio, vienen las instituciones de rendición de cuentas que se encargan de velar por ello.

Desde la perspectiva constitucional, la Sala de lo Constitucional, en la sentencia emitida en el proceso de inconstitucionalidad 21-2020 Ac, del 8 de junio de 2020, reconoce a la Constitución como distribuidora por excelencia de las atribuciones y competencias entre los órganos contenidos en ella. Asimismo, señala que la capacidad de limitar el ejercicio del poder se concreta en tres tipos de normas: las prohibiciones, relacionadas con lo que no se puede decidir; las órdenes o mandatos, y las prescripciones habilitantes, ámbito en el que establece el margen estructural confiado por la carta magna a los entes públicos.

La misma sentencia también reconoce como dos estados de cosas vitales: (i) la separación orgánica de funciones, reconocida en el artículo 86 inc. $1 .^{\circ} \mathrm{Cn}$., como principio constitucional fundamental para la democracia republicana "que debe incidir en la interpretación de la ley", y (ii) el equilibrio de los frenos $y$ contrapesos en el ejercicio del poder.

Por su parte, la sentencia emitida en el proceso de inconstitucionalidad 6-2020 Ac, ya citada, consideró que son las disposiciones constitucionales orgánicas las que definen la estructura general del Estado, que se articula en órganos que ejercen el poder público a través de autoridades que los integran. Este entramado se desarrolla conforme a las competencias que se les otorgan bajo un sistema de mecanismos de interacción e incidencia común que configura el sistema de controles para equilibrar la relación entre los órganos y "evitar poderes omnímodos o sin control".

Asimismo en la sentencia dictada el 10 de junio de 2005, en el proceso de inconstitucionalidad 60-2003, la Sala refirió que la Constitución "ordena los cometidos de los distintos detentadores del poder de manera que se posibilite la complementariedad de estos entre sí y que se garantice la responsabilidad, el control y la limitación del poder en el proceso de adopción de las decisiones estatales". En consecuencia, la distribución de atribuciones y competencias de los distintos órganos constitucionalmente establecidos asegura el desarrollo de la teoría de 
los controles en la interacción en el proceso político.

Además, en la misma resolución, la SC desarrolla dos tipos de técnicas de control al ejercicio del poder: (a) los intraorgánicos, que operan dentro de cada uno de los órganos, y (b) los interorgánicos, que funcionan cuando los diversos titulares interactúan y cooperan en la gestión estatal, (b.i) ya sea en una actuación conjunta controlándose entre sí al compartir el ejercicio de la función o (b.ii) los que intervienen discrecionalmente autorizados por la Constitución en la actividad de otra institución que detenta el poder, tal como ocurre con la Asamblea Legislativa sobre los demás órganos del Estado, especialmente en el caso de análisis del órgano ejecutivo.

\section{Instituciones y prácticas de rendición de cuentas sobre el órgano ejecutivo}

En El Salvador, la accountability horizontal es ejercida por instituciones según el ámbito de su especialización y carácter técnico que las reviste. Las instituciones objeto de la investigación son aquellas enfocadas en la formulación o implementación de políticas públicas, en términos de planes, programas y proyectos, llevadas a cabo por ministerios y secretarías del órgano ejecutivo, así: la Corte de Cuentas de la República, la Fiscalía General de la República, la Procuraduría para la Defensa de los Derechos Humanos, el Instituto de Acceso a la Información Pública, el Tribunal de Ética Gubernamental, el Tribunal Supremo Electoral, la Sección de Probidad de la Corte Suprema de Justicia, la Sala de lo Constitucional, la Sala de lo Contencioso Administrativo, la Asamblea Legislativa y los tribunales que integran el órgano judicial.

Es importante recordar, como se dijo supra, que las prácticas de rendición de cuentas de estas instituciones son una expresión del $\mathrm{L}$ del $\mathrm{P}$, tanto de requerirle al $\mathrm{A}$ la información y la justificación de sus decisiones y acciones en su ámbito de actuación o $\mathrm{D}$, así como de sancionarlo si la información y explicación requerida no es satisfactoria.

Para poder evidenciar cómo opera el marco regulatorio en la rendición de cuentas, se hará un análisis más extenso sobre las prácticas de tres instituciones, cuyas consecuencias cobran trascendencia al abordar distintas esferas del quehacer gubernamental y el señalamiento de graves deficiencias en el trabajo del Ejecutivo: la Asamblea Legislativa, la Sala de lo Constitucional de la Corte Suprema de Justicia y la Corte de Cuentas de la República.

Las disposiciones de las primeras dos instituciones tienen efectos directos $e$ inmediatos en toda la población. No obstante, es importante destacar uno de los elementos que desmarca una institución de la otra: el carácter político partidista que caracteriza a la Asamblea Legislativa versus la Sala de lo Constitucional.

Por otra parte, en una concepción ligera, parecería que las disposiciones de la Corte de Cuentas involucran únicamente al funcionario público o contratista privado que ha hecho una mala ejecución de los fondos gubernamentales. Sin embargo, el peso de las decisiones que toma la Corte de Cuentas es tal que podría significar recuperar o perder millones de dólares que anualmente el órgano ejecutivo invierte en programas y proyectos.

En las "Encuestas de evaluación" de los años 2000, 2005 y 2010 que publica el Instituto Universitario de Opinión Pública (IUDOP) de la Universidad Centroamericana José Simeón Cañas, al preguntar a la población encuestada cuál es el nivel de confianza que tiene en la Asamblea Legislativa, se observa un crecimiento sostenido a través del tiempo de aquellos que contestaron "nada", pasando de un $32.5 \%$ de los encuestados a un $41.8 \%$. En el caso de la Corte Suprema de Justicia, el nivel de desconfianza de los salvadoreños fue variable, alcanzado el mayor porcentaje de personas en el 2005.

En los informes titulados "La percepción de la seguridad y la confianza en las instituciones públicas", publicados en los años 2013, 
2016 y 2017 por la Agencia de los Estados Unidos para el Desarrollo Internacional (USAID, por sus siglas en inglés) y el IUDOP, se preguntó a la población salvadoreña encuestada sobre su nivel de satisfacción con el trabajo realizado por estas tres instituciones. Mientras que el porcentaje de los encuestados que respondieron "nada satisfechos" aumentó cada año para el trabajo que realiza la Asamblea Legislativa y la Corte de Cuentas, para la Corte de Suprema de Justicia hubo una levísima disminución en la cantidad de personas "nada satisfechas" en 2016, que volvió a subir para 2017, así como se ilustra en la figura 1.

Figura 1. Desconfianza e insatisfacción de la población en las instituciones

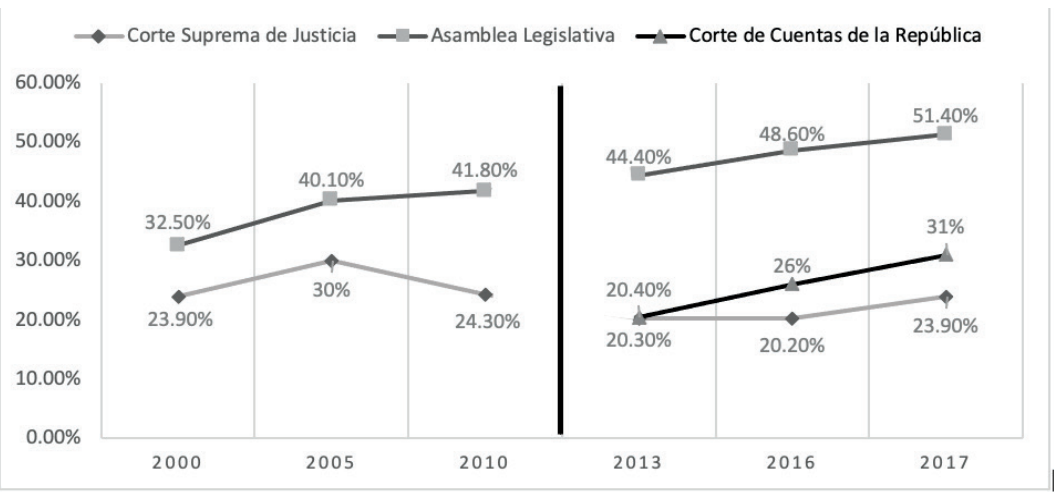

Fuente: elaboración propia con base en la encuestas de IUDOP (2000, 2005 y 2010), así como en los informes de IUDOP (2013, 2016 y 2017). Los porcentajes retomados son del sector encuestado que manifestó no tener "nada" de confianza (entre los años 2000-2010) y "ninguna satisfacción” (entre 2013-2017) en el trabajo de las instituciones.

Aunque las razones de tales variaciones en el porcentaje de la población que rechaza el quehacer de estas instituciones pueda deberse a situaciones diversas (como la conformación subjetiva de ellas, el contexto político, la coyuntura social o económica, etc.), tal como menciona Estella de Noriega (2020), "nada repercutira más directamente en nuestro grado de confianza que la actitud y la conducta de aquella persona o institución en la que la depositamos" (p. 7).

\subsection{Asamblea Legislativa}

La Asamblea Legislativa es el órgano constitucionalmente establecido para la producción de leyes; no obstante, para el interés del presente artículo, será analizada en su función de institución de control interorgánico sobre el órgano ejecutivo. En la sentencia pronunciada el 25 de mayo de 2011, en el proceso de inconstitucionalidad 85-2010, la Sala de lo Constitucional refirió como ejemplos de las facultades de la Asamblea Legislativa en su modalidad de intervención $y$, por ende, de control: "aprobar o desaprobar los informes de los ministros (art. 131, ord. 18. , Constitución de la República, en adelante Cn.); nombrar Comisiones Parlamentarias de Investigación (art. 131, ord. 32., Cn.); interpelar a funcionarios (art. 131, ord. $34 .^{\circ}, \mathrm{Cn}$.); recomendar la destitución de funcionarios (art. 131 , ord. $\left.37 .^{\circ}, \mathrm{Cn}.\right) "$, al considerar que estas prácticas de control político "tienen por objeto la valoración de actuaciones de otros órganos o entes públicos, desde criterios constitucionales, legales o políticos y con respeto a las competencias constitucionalmente asignadas".

A continuación serán abordadas las prácticas de rendición de cuentas que están directamente relacionadas con el desempeño 
de la función pública de quienes integran el Consejo de Ministros: (1) la aprobación o desaprobación del informe de labores, (2) interpelación a ministros y titulares de instituciones, (3) análisis del Proyecto de Presupuesto General del Estado y (4) la integración de comisiones especiales.

\subsubsection{La aprobación o desaproba- ción del informe de labores}

La práctica de control sobre el informe de labores del Ejecutivo del año transcurrido, presentado por los ministros dentro de los dos meses siguientes a la terminación de cada año, tiene por fundamento constitucional los arts. 167, nums. 6 y 131, ord. 18. ${ }^{\circ}$, que obliga a la Asamblea Legislativa a recibirlo y aprobarlo o desaprobarlo.

$\mathrm{El}$ art. 104 del Reglamento Interior de la Asamblea Legislativa (RIAL) fija como contenidos mínimos de los referidos informes:

1. El resumen ejecutivo del contenido del documento.

2. La exposición de los objetivos, las metas y los resultados obtenidos por la institución, en el período que informa.

3. El plan de trabajo del período.

4. El detalle del presupuesto asignado y ejecutado, así como las obras pendientes, de acuerdo con el presupuesto.

5. Los logros obtenidos y el listado de los sectores favorecidos durante la gestión. Esta información se respaldará con documentos y datos estadísticos.

Estos informes son presentados como correspondencia por el titular o un encargado de despacho para ser analizados por la comisión respectiva y emitir el dictamen de aprobación o desaprobación en un plazo no mayor de noventa días después de presen- tado. El titular de la institución podría ser convocado a solicitud de la comisión respectiva para brindar las ampliaciones que dicha instancia le requiera.

Si transcurrido el periodo fijado para el análisis y la emisión del dictamen, la comisión no lo ha emitido, la Junta Directiva de la Asamblea remite el expediente del informe al Pleno para que lo apruebe o no. Debe señalarse que todo dictamen, tanto de aprobación como de desaprobación, debe contener una justificación razonada del cumplimiento o no de las formalidades y del fondo de este informe.

De ser aprobado o no por el Pleno, se emite el acuerdo respectivo y se publica en el Diario Oficial. El art. 108, RIAL expresamente establece que en caso de desaprobación se comunica al presidente de la República. Además, el Pleno podría crear una comisión legislativa especial para que investigue a la institución.

Ante el incumplimiento de la presentación del informe de labores de la Administración Pública, el ministro queda depuesto, decisión de la que será notificado el presidente de la República para que nombre el sustituto. El nuevo funcionario nombrado está obligado a presentar el respectivo informe dentro de los treinta días siguientes y de incumplir también quedará depuesto, de conformidad con el art. 168 , ord. $6 .^{\circ}$, inc. $2, \mathrm{Cn}$.

Asimismo, para el caso del ministro de Hacienda, el art. 168, ord. 6..$^{\circ}$ inc. 1, la Constitución prevé la presentación de un informe especial dentro de los tres meses siguientes a la terminación de cada período fiscal. Es decir, antes del 1 de abril, sobre la cuenta general del último presupuesto y el estado demostrativo de la situación del Tesoro Público y del Patrimonio Fiscal. El proceso de esta práctica de control político se ilustra en la figura 2, así:

Figura 2. Proceso de aprobación o desaprobación de informe de labores por parte de la Asamblea Legislativa 


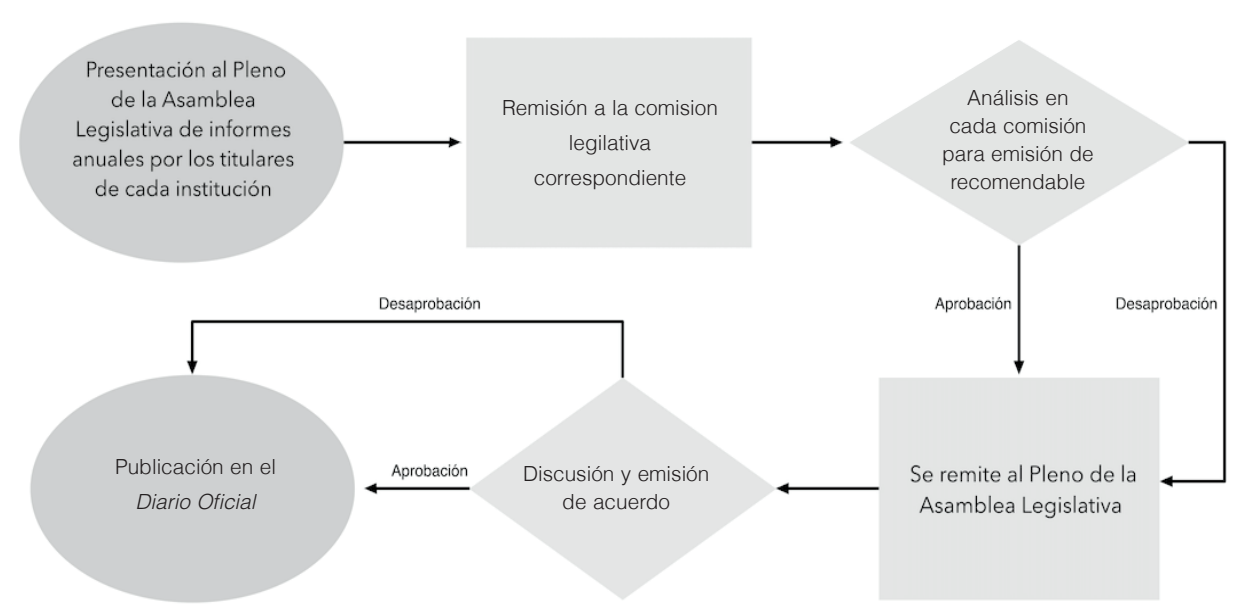

Si el titular de una Institución no presenta el informe correspondiente se informará al presidente de la República, que deberá destituir al funcionario y presentar en siguientes días el informe correspondiente.

Fuente: elaboración propia, con base en la Constitución de la República de El Salvador y el Reglamento Interior de la Asamblea Legislativa.

A pesar de que el texto plantea una considerada planificación y formalismo que envuelven la redacción, presentación y evaluación de los informes de labores, al llevarlo a la práctica, se aprecian grandes deficiencias presentes, desde la formulación de los mismos hasta su valoración. Como se adelantaba, lo que en realidad llega a manos de las comisiones legislativas son memorias de labores, documentos donde, tal como colocan de forma automática las instituciones gubernamentales en los sitios web de transparencia, "se reflejan las principales apuestas de la actual gestión y las labores hechas en materia de..." y agregan el ramo que les corresponde.

Formalmente, podría ser válido que estos documentos sean presentados como los "informes" que requiere la Constitución, pues en realidad sí cumplen - en mayor o menor medida - con todos los requisitos que el RIAL establece para tal propósito. Sin embargo, lo que se hace en tales legajos es una mera narración de los programas y sus respectivos proyectos llevados a cabo por una Administración Pública en un período determinado (normalmente el año).

Dentro de dicha narración, a efecto de cumplir con el resto de requisitos, se colocan diversas tablas y gráficos, cuya aparición a veces parece forzada y que no guarda relación alguna con el resto de la narración, donde se colocan los montos asignados a tal o cual obra y el porcentaje de avance de las mismas, o las estimaciones de población beneficiada. ${ }^{5}$

El sistema de rendición de cuentas tiene como fundamento la transparencia y la comunicación con efectividad del quehacer, en este caso, del Ejecutivo, sobre todo para conocer el uso que se le ha dado a los fondos públicos. Ahora bien, lo que actualmente las memorias de labores hacen es una especie de "monitoreo", una suerte de práctica cuyo objetivo es explicar todo el universo de datos que existen sobre determinada política pública

$5 \quad$ Para tales efectos, sirvan de ejemplos las Memorias de labores del Ministerio de Salud de los años 2008 al 2020, https://www.transparencia.gob.sv/institutions/minsal/documents/memorias-de-labores. 
(dígase salud, por ejemplo), así como de todos los programas y proyectos públicos que se han llevado a cabo de forma continua durante el año (mezclando ramas como construcciones, medicamentos, enfermedades y demás temáticas cuyo único elemento en común es la salud, pero que debe estudiarse de forma distinta cada cual). Este monitoreo o seguimiento —como describe Asenjo (2016)_ es una tarea prácticamente mecánica que se "centra en recopilar de manera sistemática y continua datos con el fin de valorar el desempeño de un programa o política durante su implementación" (p. 15).

En cambio, como lo que se busca es conocer las transformaciones generadas con el impacto del trabajo de la Administración Pública, así como la gestión financiera de tal labor, es preferible que se realicen "evaluaciones" de programas y proyectos, donde de forma integral y con base en métodos y técnicas científicas previamente establecidas se estudian individualmente cada una de las "ramas", aunque pertenezcan a un mismo "árbol". Asenjo (2016), por ejemplo, establece que una diferencia fundamental entre este enfoque y el monitoreo es que logra "abordar preguntas que exceden el ámbito de aplicación del monitoreo y que también son de interés para responsables de políticas" (p. 15), va más allá de la mera narración de los hechos y lo obrado, y pasa a ser una fuente de autoaprendizaje para el Ejecutivo en la planeación o replanteamiento de futuros proyectos; una autocrítica sobre los aciertos y errores cometidos durante la implementación de lo planeado al tener, ahora sí, de forma más clara y directa, las consecuencias de la aplicación. En todo caso, el monitoreo y la evaluación no deben ser prácticas irreconciliables, sino complementarias en el seguimiento de la labor de las administraciones públicas.

Uno de los problemas que están a la base de esto es que no existen lineamientos claros de cómo se deben presentar los informes de labores, ni tampoco hay un formato estándar y generalizado, por lo que cada institución presenta información que varía y que, con los cambios de administración, pueden presentar diferencias marcadas. Sin lineamientos claros en la normativa, queda al arbitrio de las instituciones la forma en la que se presenta la información.

Por otro lado, otro de los grandes problemas en relación con los informes de labores es el sesgo político-partidista dentro de la Asamblea Legislativa, que se evidencia en las votaciones revisadas en los distintos periodos y en las publicaciones en el Diario Oficial. Aun cuando el art. 125 de la Constitución establece que los diputados de la Asamblea Legislativa representan al pueblo entero y no deben obedecer a mandato imperativo alguno, en la práctica los informes de labores son aprobados o no de acuerdo al grado de alianzas del Ejecutivo. Así, por ejemplo, si el partido del Ejecutivo posee mayoría (o un número considerable de afines) en la Asamblea Legislativa, los informes de labores no presentarán mayor discusión en las comisiones correspondientes, más allá del que pueda generar el bloque de oposición, $y$, al enviarlos al Pleno, los informes serán aprobados.

En cambio, cuando el partido de gobierno no tiene el apoyo suficiente -o ningún apoyo- por parte de la Asamblea Legislativa, el proceso de aprobación o desaprobación podría variar. En una correcta evaluación, basada en informes elaborados de forma técnica, los miembros de la comisión respectiva discutirían objetivamente si el trabajo llevado a cabo por las instituciones del Ejecutivo ha sido satisfactorio y trascendental para las poblaciones que ha sido dirigido el mismo, y si no, señalar las deficiencias encontradas. Otro elemento que evidencia esta práctica son los "votos en bloque" a partir de una directriz o lineamiento del jefe de bancada, y no de un riguroso análisis que responda a un verdadero ejercicio de control político.

Otro aspecto importante a considerar es que no existen repercusiones derivadas del acuerdo de desaprobación de un informe, cuando se da el caso. Tal como se aprecia 
en la figura 1, el proceso de presentación de los informes de labores termina con la publicación del resultado en el Diario Oficial y su posterior archivo. No existe, de manera directa, un seguimiento a las observaciones y críticas que hayan sido emitidas respecto del trabajo llevado a cabo por el Ejecutivo.

Ahora bien, de forma indirecta, los aciertos y desaciertos que se señalan en las comisiones legislativas pueden desencadenar consecuencias en otras prácticas de control que posee la Asamblea. Son los casos, por ejemplo, del proceso anual de aprobación del Presupuesto de Ingresos y Egresos de la Administración Pública, donde en la fase de debate y justificación de montos asignados en el proyecto de presupuesto no se logre la autorización de los fondos solicitados por no corresponderse con el impacto que en realidad genera una cartera de Estado. O más grave aún, que del estudio del trabajo llevado a cabo (o de la inactividad) sea necesaria la conformación de comisiones especiales o la celebración de un antejuicio por graves negligencias cometidas.

De la revisión efectuada en el período 1999 a 2019, no se encontró ningún caso en el que no se haya presentado el informe correspondiente; además, ante la falta de aprobación del informe por parte de la Asamblea, tampoco se derivó un proceso de interpelación del funcionario a cargo de la institución pública obligada (A) o la creación de alguna comisión de investigación. ${ }^{6} \mathrm{El} \mathrm{P}$, en esta práctica, ha actuado de forma deficiente $e$ ineficaz.

\subsubsection{Interpelación a ministros y titulares de instituciones}

La interpelación de ministros, titulares de instituciones oficiales autónomas o encargados de despacho por parte de la Asamblea Legislativa tiene como fundamento constitucional el art. 131, ord. 34. ${ }^{\circ}, \mathrm{Cn}$, estando obligados a concurrir para contestar las interpelaciones que se les hicieren y si no acuden quedarán, por el mismo hecho, depuestos de sus cargos, a tenor de lo establecido en el art. 165, Cn.

Esta práctica de control tiene por objeto que se le brinden al órgano legislativo las explicaciones de los titulares de las distintas instituciones del órgano ejecutivo sobre sus actuaciones, política, programa o proyecto específico, o sobre una cuestión de interés público, según el art. 113, RIAL.

La interpelación puede culminar, si así lo estimare el Pleno, en una recomendación de destitución del funcionario interpelado que será remitida a la Presidencia de la República o a los organismos correspondientes, si el nombramiento correspondiere a instituciones oficiales autónomas. Si la interpelación corresponde a los jefes de seguridad pública o de inteligencia de Estado por causa de graves violaciones de los derechos humanos, el acuerdo del Pleno tendrá carácter vinculante para el presidente.

La solicitud se efectúa por uno o más diputados o diputadas, quienes deberán fundamentar por escrito su solicitud y enunciar la lista de preguntas sobre las cuales habrá de interpelarse al funcionario en cuestión. Esta iniciativa es remitida a la Comisión Política de la Asamblea Legislativa para que dictamine su procedencia, pudiendo confirmar, ampliar, reformular las preguntas lo que será sometida al Pleno que deberá aprobarla o no.

De considerarse procedente a interpelación, la Asamblea fija el momento en el que se habrá de celebrar la plenaria especial para comunicarlo al funcionario interpelado, al menos quince días antes, a quien se le remitirán además las preguntas aprobadas, para que cuando comparezca las conteste en el mismo orden. Si el funcionario no se presentare por caso fortuito o fuerza mayor, deberá remitir justificación dentro de las veinticuatro horas hábiles siguientes a la hora señalada.

6 Constatado según requerimiento de información con referencia UAIP-AL-6264-19-(MM), de fecha 20 de agosto de 2019 . 
Una vez celebrada la sesión y respondidas las preguntas, podrá efectuarse repreguntas si el presidente de la Asamblea considera que no está agotado el tema. Una vez finalizado el expediente es remitido a la Comisión Política para su estudio y dictamen, el que será sometido al Pleno para su aprobación o no. El resultado de una interpelación puede ser una recomendación de la Asamblea a la Presidencia de la República de que el funcionario interpelado sea destituido. El proceso de la práctica se ilustra así:

Figura 3. Proceso de interpelación a ministros y titulares de instituciones

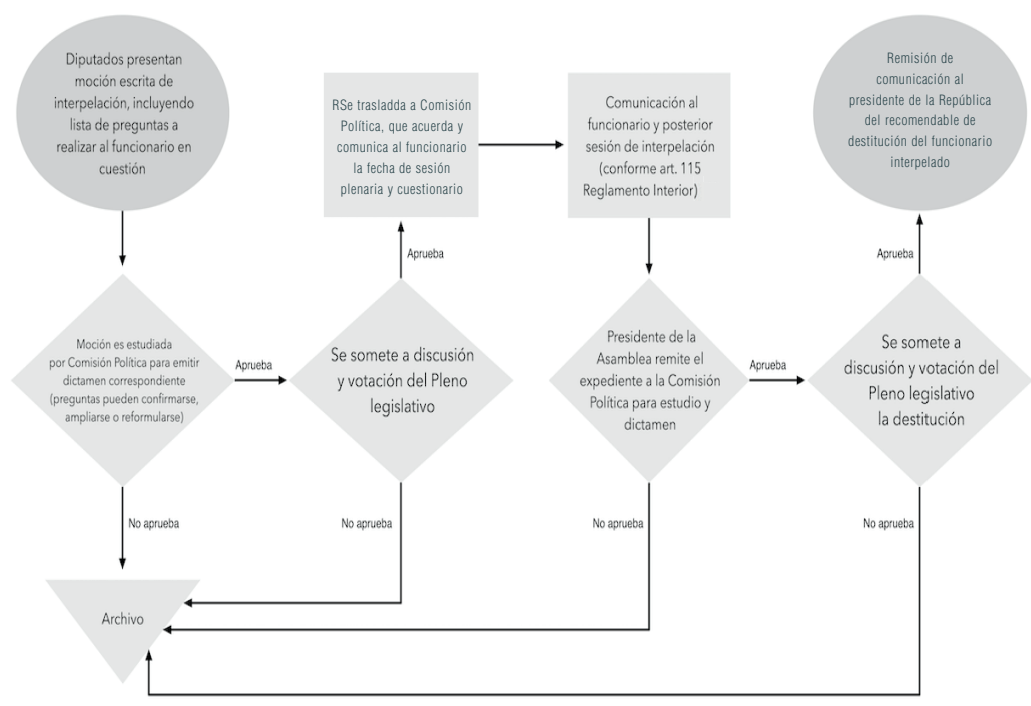

Fuente: elaboración propia con base en la Constitución de la República de El Salvador y el Reglamento Interior de la Asamblea Legislativa.

En el período comprendido entre 1999 y 2019, no se activó esta práctica de control institucional; no obstante, en contraste, vale la pena mencionar que, durante 2020, la Asamblea Legislativa interpeló a tres funcionarios: (i) dos para recibir explicaciones: (1) de Ana Orellana Bendek, ministra de Salud, y (2) de Frederick Benítez, presidente de la Administración Nacional de Acueductos y Alcantarillados (ANDA) sobre la calidad y distribución del agua suministrada a los hogares salvadoreños en los meses de enero y febrero de 2020, y (ii) una relacionada con la intervención y el rol de las Fuerzas Armadas
(FF. AA.) en la toma de las instalaciones del órgano legislativo el 9 de febrero de 2020, siendo convocado para tal efecto (3) el ministro René Merino Monroy.

En los tres casos, la recomendación fue la destitución y, aunque dos de ellos fueron destituidos, al menos públicamente no fueron relacionadas las recomendaciones correspondientes con la decisión presidencial. De igual forma ocurrió en 1997, cuando la Asamblea Legislativa, producto de una interpelación, recomendó destituir al entonces presidente del Banco Central de Reserva (Roberto Orellana 
Milla), pero el presidente Calderón Sol tomó su decisión ocho meses después.

\subsubsection{Análisis, aprobación y segui- miento del proyecto de Presupuesto General del Estado}

El proceso anual de aprobación del Presupuesto de Ingresos y Egresos de la Administración Pública, así como su seguimiento, es un mecanismo de control de la Asamblea Legislativa sobre el órgano ejecutivo.

El marco normativo de esta práctica tiene por fundamento la Constitución de la República en el art. 131, ordinal 8. , que faculta a la Asamblea Legislativa a decretar el Presupuesto de Ingresos y Egresos de la Administración Pública (PIEAP), así como sus reformas. En contraposición, el art. 167, ord. 3. ${ }^{\circ}$, Cn deja al Consejo de Ministros la elaboración del proyecto de presupuesto de ingresos y egresos y su presentación a la Asamblea Legislativa, así como las transferencias entre partidas de distintos ramos de la Administración Pública.

A partir de la revisión de la Constitución, la Ley Orgánica de la Administración Financiera del Estado $(\mathrm{LOAF})^{7}$, así como su Reglamento (RLOAF); la Ley de Responsabilidad Fiscal para la Sostenibilidad de las Finanzas Públicas y el Desarrollo Social $(\mathrm{LRF})^{8}$; el Reglamento Interior del Órgano Legislativo (RIAL) ${ }^{9}$ y el Reglamento Interno del Órgano Ejecutivo (RIOE), el proceso de aprobación del PIEAP se describe en dos momentos: (i) desde la formulación hasta su aprobación y (ii) desde su aprobación hasta las modificaciones que deban ser efectuadas durante su ejecución.

\section{i) El proceso del presupuesto desde su formulación hasta su aprobación}

El art. 4, LOAF faculta al ministro de Hacienda a entregar cada año al presidente de la República los anteproyectos de Presupuesto General del Estado, cuya estructuración deben regirse por los principios presupuestarios de universalidad, unidad, equilibrio, oportunidad y transparencia.

El proceso de formulación inicia con la elaboración de la Política Presupuestaria efectuada por el Ministerio de Hacienda a través de la Dirección General de Presupuesto (DGP), a partir de los planes y políticas de gobierno, incluyendo el plan general del Gobierno, establecido en el art. 167, num. 2, $\mathrm{Cn}$, programa monetario, metas y prioridades institucionales y evaluación de los resultados del presupuesto cerrado contablemente del año precedente. También deberá tener en cuenta la estimación de ingresos, a fin de mantener el equilibrio presupuestario y el techo aprobado para cada institución.

Según el art. 6, LRF el Presupuesto General del Estado y las proyecciones fiscales deben elaborarse sobre un escenario económico base que considerará tanto las estimaciones oficiales de las variables macroeconómicas del Gobierno como de los organismos internacionales, elemento que además contribuye con el Marco Fiscal de Mediano y Largo Plazo (MFMLP), que responde al principio de presupuesto de mediano plazo que establece que la preparación del Presupuesto General del Estado debe enmarcarse en un escenario macroeconómico y presupuestos indicativos a cuatro años (art. 2, b) LRF).

La planificación y los lineamientos para la elaboración del Presupuesto, establecidos por la DGP según el art. 23, c), LOAF implican, además, analizar e integrar los proyectos de

\footnotetext{
7 Decreto Legislativo N. ${ }^{\circ}$ 516, de 23 de noviembre de 1995, publicado en el Diario Oficial N. ${ }^{\circ}$ 7, tomo 330 , del 11 de enero de 1996.

8 Decreto Legislativo de 10 de noviembre de 2016, publicado en el Diario Oficial N. ${ }^{\circ} 210$, tomo 413, del 11 de noviembre de 2016.

9 Decreto del Consejo de Ministros N. ${ }^{\circ} 24$, del 18 de abril de 1989, publicado en el Diario Oficial N. ${ }^{\circ} 70$, del $_{18}$ de abril de 1989.
} 
presupuesto que remitan las entidades del sector público y sugerir ajustes que considere. En la práctica, esta sugerencia se convierte en un ajuste de los proyectos de presupuestos remitidos a los techos presupuestarios que se fijan para cada entidad.

Una vez elaborados los lineamientos, al ministro de Hacienda le corresponde presentar al presidente de la República, a más tardar en la segunda quincena del mes de abril de cada año, la política presupuestaria (PP) para que sea sometida a discusión y aprobación del Consejo de Ministros. Esta política determina las orientaciones y prioridades, y estima la disponibilidad de recursos, techos financieros y variables básicas para la asignación a cada institución; además de las normas, métodos y procedimientos para la elaboración de los proyectos que cada entidad debe presentar al Ministerio de Hacienda a finales de julio.

Aprobada la PP en el Consejo de Ministros, debe ser distribuida a cada institución del sector público para que estas elaboren sus proyectos presupuestarios, que deberán ser remitidos al Ministerio de Hacienda para que los considere y establezca en los plazos que la DGP establezca. De no hacerlo, será el Ministerio de Hacienda el que efectúe los ajustes al presupuesto y considerar el nuevo presupuesto en los montos y rubros que estén consignados en el de ejecución. La institución que advierta que no podrá cumplir con el tiempo otorgado puede solicitar prórroga.

Remitidos los presupuestos de cada institución, la DGR consolida y entrega al ministro para que someta a consideración del Consejo de Ministros el proyecto de Ley de Presupuesto General del Estado y de los Presupuestos Especiales, así como de la Ley de Salarios para cada ejercicio, para el que la DGP debe acompañar:

a. Mensaje presupuestario, que contenga análisis macroeconómico y financiero sobre las variables que se hayan tomado en cuenta para elaborar su presupuesto; b. Proyectos de Ley del Presupuesto General, Presupuestos Especiales y Ley de Salarios del Estado;

c. Un resumen del Presupuesto General del Sector Público No Financiero, el cual es el consolidado de los presupuestos mencionados en el literal anterior y de los Presupuestos Extraordinarios;

d. Normas que regulen la ejecución presupuestaria, y

e. Anexos financieros y resúmenes de sus principales componentes.

Con la aprobación, el Consejo de Ministros, antes del 1 de octubre de cada año, debe presentarlo ante la Asamblea Legislativa y acompañarlo con los siguientes documentos establecidos en el art. 48, RAFI:

a. Situación financiera del Gobierno central al principio del ejercicio corriente;

b. Cifras reales sobre la ejecución de los presupuestos del ejercicio anterior;

c. Cifra de los gastos efectivamente realizados y compromisos pendientes del ejercicio corriente y la estimación del total de rentas y de gastos para el mismo ejercicio;

d. Situación financiera del Gobierno central calculada al final del ejercicio corriente;

e. Equilibrio entre los recursos calculados y las asignaciones recomendadas;

f. Cualquier otra información estadística que sea útil para la consideración de los presupuestos.

Además, a partir de lo dispuesto en el art. 28, LRF, deben incluirse:

g. Declaración jurada de fiel cumplimiento a lo establecido en el art. 227, Cn y de veracidad e inclusión completa de todos los egresos corres- 
pondientes al proyecto de Ley de Presupuesto General de la Nación.

\section{ii) Desde su aprobación hasta las modificaciones que deban efectuarse durante su ejecución}

Los titulares del órgano ejecutivo tienen, entre otras facultades relacionadas con la Ley AFI, tramitar ante la DGP las modificaciones relacionadas con transferencias de asignaciones entre distintos ramos y organismos para su aprobación por la Asamblea Legislativa.
En este caso, deberán presentar al Ministerio de Hacienda mediante solicitud del titular los requerimientos necesarios, y este presentar a la Asamblea Legislativa, la solicitud de modificación presupuestaria, la que será tramitada ante la Comisión de Hacienda y Especial de Presupuesto, que con dictamen favorable remite al Pleno para su aprobación y su posterior sanción por el presidente de la República y la correspondiente publicación en el Diario Oficial.

Figura 4. Análisis, aprobación y seguimiento del proyecto de Presupuesto General del Estado

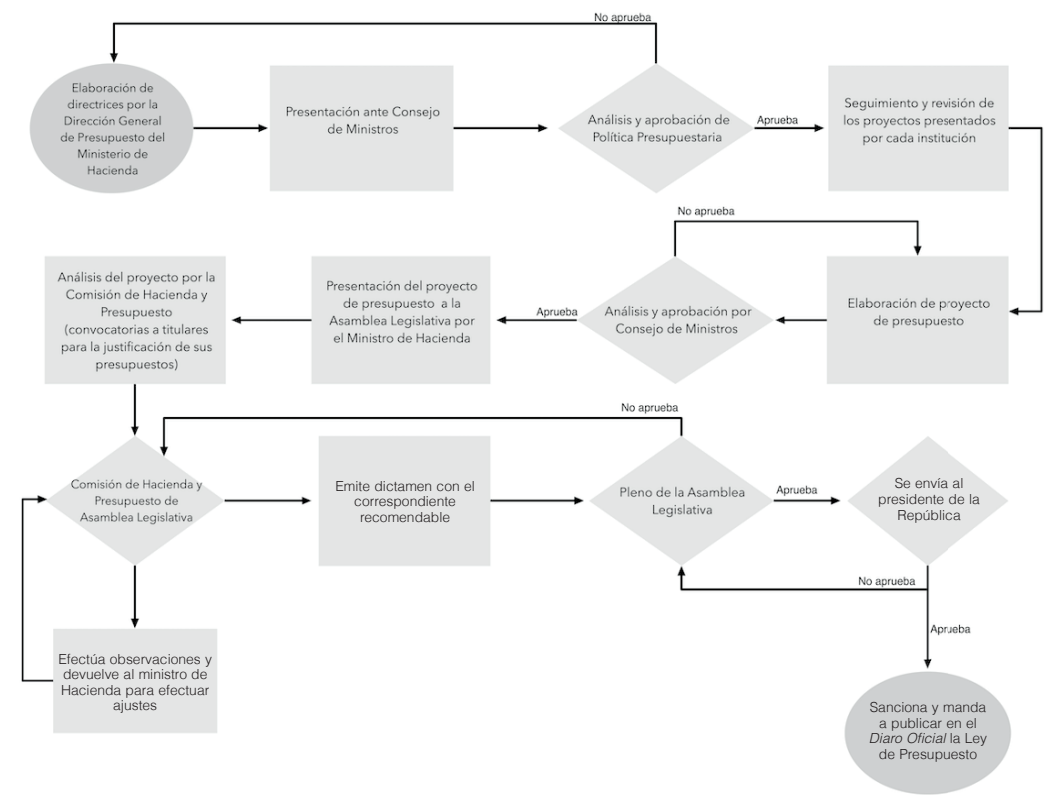

Fuente: elaboración propia con base en la Constitución, la Ley Orgánica de la Administración Financiera del Estado, así como su Reglamento; la Ley de Responsabilidad Fiscal para la Sostenibilidad de las Finanzas Públicas y el Desarrollo Social; el Reglamento Interior del Órgano Legislativo y el Reglamento Interno del Órgano Ejecutivo. 


\subsubsection{Integración de comisiones especiales}

El Informe Único de la Comisión de Estudio del Proyecto de Constitución determinó que hay situaciones que, sin llegar a constituir delitos, "afectan seriamente la vida política de la República y que pueden tener relación con las actuaciones de funcionarios que se exceden en el ejercicio de sus funciones, que incumplen disposiciones legales expresas o en fin, que comprometen en alguna forma el buen nombre de la República", por lo que faculta a la Asamblea Legislativa para nombrar comisiones de investigación, y aclaró que "[n]o se trata de una constante interferencia en los actos de la Administración Pública sino de la investigación excepcional de hechos que puedan tener graves consecuencias políticas y que sean de interés nacional" (p. 19).

La Asamblea Legislativa está facultada por el art. 131, ord. 32. ${ }^{\circ}$, Cn para nombrar comisiones especiales para la investigación de asuntos de interés nacional que culminan, a partir del informe de estas, en la adopción de acuerdos o recomendaciones. Este interés nacional fue definido por la Sala de lo Constitucional, en la sentencia emitida en la Inc. 85-2020, como aquellos "asuntos relevantes para la ciudadanía o la opinión pública, entendiendo esta, en su dimensión más objetiva y sustancial, como una institución política fundamental indisolublemente ligada al pluralismo político, esencial para el funcionamiento constitucional y democrático".

El presidente de la República tiene, según el art. 167, ord. 7. ${ }^{\circ}$, Cn, la obligación de dar a la Asamblea Legislativa los informes que le solicite, siendo la única excepción los planes militares secretos, porque aun las negociaciones políticas que deban ser reservadas serían conocidas en una sesión especial de carácter secreto. Esta práctica evidencia el amplio acceso que tiene la Asamblea Legislativa a la información generada por el órgano ejecutivo.

Adicionalmente, el art. 132, Cn obliga a todos los funcionarios y empleados públicos, incluyendo a los de instituciones oficiales autónomas y a los miembros de la Fuerza Armada, a colaborar, comparecer o declarar ante estas comisiones; en caso contrario, pueden ser apercibidos conforme al procedimiento judicial en virtud del cual, atendiendo a lo regulado en el art. 165 del Código Procesal Penal, se ordena la citación del servidor público mediante cualquier medio de comunicación que garantice la autenticidad del mensaje, haciéndole saber el objeto de la citación, el procedimiento que se sigue y la advertencia de que de no obedecer la orden, salvo justa causa, será conducido por la seguridad pública.

Si bien las conclusiones de las comisiones especiales de investigación no son vinculantes para el órgano judicial, el resultado debe ser comunicado a la Fiscalía General de la República para que en cumplimiento de sus funciones ejerza las acciones legales que correspondan.

Además, puede ser remitida al presidente de la República o a una institución oficial autónoma una recomendación de destitución, según lo establece el art. 131, ord. $34 .^{\circ}, \mathrm{Cn}$. 
Figura 5. Proceso de integración de comisiones especiales

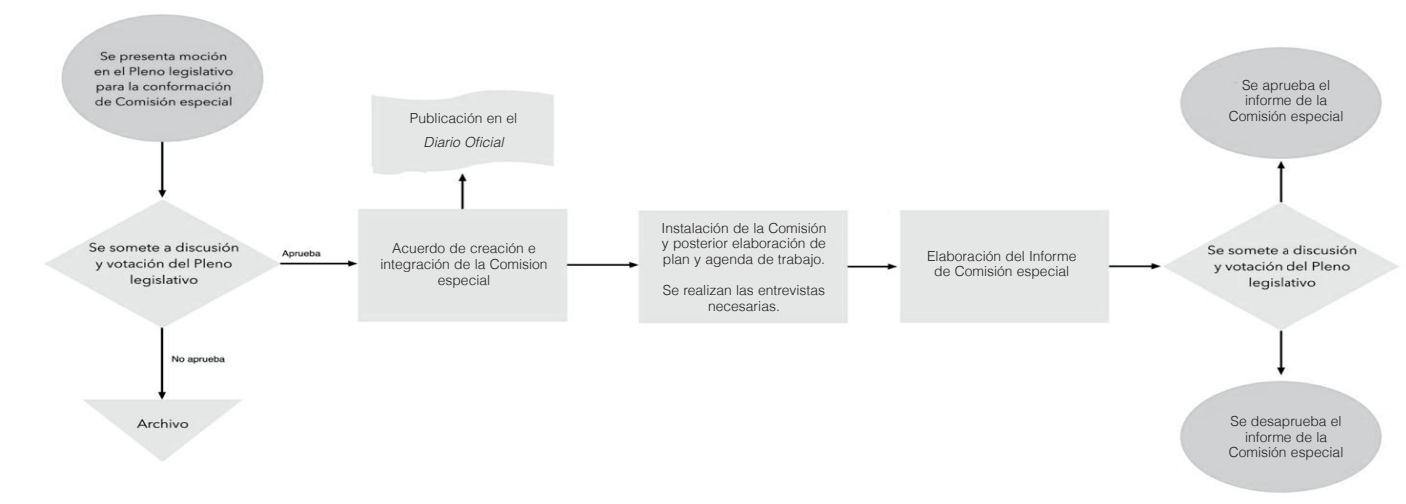

Fuente: elaboración propia, con base en la Constitución de la República de El Salvador y el Reglamento Interior de la Asamblea Legislativa.

Según la sentencia dictada en el proceso de inconstitucionalidad 60-2003, del 10 de junio de 2005, la Sala de lo Constitucional consideró como grandes rasgos característicos de las comisiones especiales parlamentarias los siguientes:

a. Naturaleza auxiliar, sin autonomía, dependientes de la Asamblea Legislativa, en el marco de la cual desarrollan sus actividades.

b. Entes políticos sin funciones jurisdiccionales $y$, por ende, con resoluciones carentes del carácter de cosa juzgada.

c. Configuración colegiada de su voluntad.

d. Naturaleza temporal y específica.

En cuanto a su existencia, son un instrumento ocasional de investigación, pues solo deben utilizarse por la Asamblea para cuestiones de singular importancia. $\mathrm{O}$, como para el caso salvadoreño, señala el art. 131, ord. 32. ${ }^{\circ}$, Cn., para la investigación de "asuntos de interés nacional".
Adicionalmente, en la sentencia de inconstitucionalidad 85-2010, la Sala amplió su criterio al considerar que siendo el control parlamentario, no administrativo, se garantiza que la Asamblea Legislativa no interfiera ni en las esferas de la Administración Pública ni en la jurisdicción. En cuanto a la naturaleza de la investigación, determinó que debía ser sobre hechos ciertos, no en desarrollo o futuros. Esta práctica fue considerada por la Sala como "instrumentos que pueden cumplir una tarea importante para el correcto funcionamiento del sistema democrático" 10 .

Sobre los límites de actuación de las referidas comisiones, enumeró: a) la autonomía orgánico-funcional de los demás órganos constitucionales del Estado; b) el objeto de interés nacional, el interés público de la colectividad; c) los derechos fundamentales y el orden constitucional en general.

\subsection{Sala de lo Constitucional}

Como se ha podido vislumbrar a través de la jurisprudencia citada hasta acá, otro de los órganos que ejerce control es la Sala de lo Constitucional. Orgánicamente, esta

10 Sentencia pronunciada en proceso de Inc. 85-2010 el 25 de mayo de 2011. 
forma parte de la Corte Suprema de Justicia; sin embargo, funciona como un verdadero tribunal constitucional. Esta Sala es la máxima intérprete de la Constitución y su jurisprudencia irradia las demás salas, tribunales, funcionarios y ciudadanía en general.

La Sala de lo Constitucional tiene diversas atribuciones; no obstante, en función de las precisiones que se han hecho en la investigación, a continuación se examinará la práctica de control que interesa: los procesos de inconstitucionalidad cuya función exclusiva le corresponde a la Sala, en virtud de los arts. 174 y 183, Cn y, en particular, a efectos de este artículo, aquella normativa que ha sido emitida por el Ejecutivo o que ha sido promovida por este.

\subsubsection{Inconstitucionalidad de leyes, decretos y reglamentos}

La normativa que rige la Sala de lo Constitucional es la Constitución, la Ley de Procedimientos Constitucionales (LPC) y el Código Procesal Civil y Mercantil (CPCM), con carácter supletorio. En particular, lo referente a esta función de la Sala se encuentra en los arts. 138, 174 y 183, Cn.

El proceso de inconstitucionalidad tiene por objeto verificar la conformidad o contradicción de cualquier norma infraconstitucional de carácter general y abstracto (ley, reglamento, ordenanza, etc.), o bien de un acto concreto ejecutado por órganos constitucionales en aplicación directa de la Constitución, a fin de invalidar cualquier precepto normativo que contraríe algún mandato constitucional. En definitiva, lo que se busca es establecer si existe una confrontación normativa entre la disposición impugnada y el texto constitucional. Si es así, la disposición es expulsada del ordenamiento jurídico.

El proceso puede iniciar a través de dos vías: (i) demanda ciudadana (de conformidad con los arts. 2, LPC y $174, \mathrm{Cn}$ ) y (ii) requerimiento judicial (según los arts. 77-A, LPC y $185, \mathrm{Cn})$.

\section{i) Demanda ciudadana}

Los arts. 6-11 y 77-A-77-F, LPC establecen cómo se da el trámite del proceso de inconstitucionalidad. El art. 6, LPC establece que debe presentarse una demanda por escrito en la que se señale nombre, profesión $\mathrm{u}$ oficio $\mathrm{y}$ domicilio del o la peticionaria, incluyendo documentos que acrediten su ciudadanía.

En la demanda, debe quedar correctamente establecida la norma controvertida, que puede ser una ley, decreto o reglamento, así como el número y la fecha del Diario Oficial en el que ha sido publicado. Aspecto fundamental a establecer en una demanda de inconstitucionalidad es el objeto de control (la disposición controvertida) y el parámetro de control (la disposición constitucional que se está vulnerando). Por ello, en la demanda se deben exponer con claridad el contenido normativo y los motivos de la inconstitucionalidad, citando los artículos pertinentes de la Constitución.

La demanda se examina en cuanto a su forma y su contenido. El examen de forma verifica que la demanda lleve todos los requisitos que establece el art. 6, LPC, mientras que el examen de fondo verifica que se configure correctamente la pretensión objeto del proceso y verifica la procedencia de la demanda.

La Sala de lo Constitucional puede advertir sobre el incumplimiento de requisitos formales y otras imprecisiones de la pretensión. El demandante puede subsanar las faltas que le sean señaladas. Si este subsana fuera de plazo o no lo hace correctamente, la demanda se declara inadmisible.

Si las fallas en la demanda no son susceptibles de ser subsanadas o se refieren más al fondo del asunto, se declarara improcedente.

Las causales de improcedencia pueden ser:

a. Que la norma impugnada ya no pertenezca al ordenamiento jurídico. 
b. Que haya un pronunciamiento desestimatorio previo respecto de los mismos motivos de inconstitucionalidad planteada.

c. Que haya una errónea atribución del contenido normativo del parámetro de control.

d. Que se plantee la vulneración de derechos en la esfera jurídica particular del peticionario (ya que eso es materia de amparo).

e. Que la supuesta inconstitucionalidad se base en supuestos hipotéticos de aplicación de la norma impugnada.

f. Que se plantee como parámetro de control una disposición infraconstitucional.

Una vez admitida la demanda, se emite un auto en el que se establece el objeto y parámetro de control y el contraste. De igual manera, en atención al art. 7, LPC se solicita informe a la autoridad que haya emitido la disposición impugnada. El plazo para presentar el informe es de diez días y debe ir acompañado de la documentación pertinente que fundamente su argumento.

De conformidad con el art. 8, LPC, una vez vencido el plazo, se le da traslado al fiscal general de la República, quien se manifiesta sobre la pretensión en un plazo máximo de 90 días.

En estas fases, lo que interesa es el cumplimiento del plazo; es decir, la sentencia que emana de la Sala de lo Constitucional se da con independencia de que una o ambas autoridades, a quienes se les dio traslado, hayan emitido los informes correspondientes.

En la resolución, la Sala de lo Constitucional toma en cuenta la argumentación de los distintos intervinientes. A su vez, acompaña el fondo de la resolución de doctrina y jurisprudencia, ya sea propia o de tribunales internacionales, incluyendo los regionales y universales. En principio, la Sala se ciñe a sus precedentes; sin embargo, puede cambiar los mismos argumentando la razón del cambio. Sobre este punto se volverá más adelante.

La sentencia que emite la Sala de lo Constitucional puede ser estimatoria o desestimatoria. Si es estimatoria, la consecuencia es que se ordena la expulsión del precepto normativo. Si es desestimatoria, significa que se rechaza la inconstitucionalidad incoada.

De esta manera y de conformidad con el art. 10, LPC, la sentencia es de obligatorio cumplimiento para todos y todas de un modo general. Esto incluye todos los órganos del Estado, funcionarios, autoridades, así como a personas naturales y jurídicas. Asimismo, la sentencia no admite recurso alguno.

Posteriormente, la sentencia se publica en el Diario Oficial dentro de los quince días siguientes a la resolución. Si el director de este se negase a publicar la sentencia, se ordenará su publicación en uno de los diarios de circulación diaria y nacional.

Es importante mencionar que el proceso de inconstitucionalidad también puede finalizar de manera anormal en cualquier etapa, por lo que el proceso se sobresee. Esto se da cuando se advierte o sobreviene algún motivo que impida o vuelva innecesario el análisis de constitucionalidad.

\section{ii) Requerimiento judicial}

Por otra parte, los jueces también pueden iniciar un requerimiento, de conformidad con el art. 77-F, LPC. El juez ordinario (es decir, el que no integra la Sala de lo Constitucional) tiene la facultad de declarar la inaplicabilidad de cualquier ley o disposición de los otros órganos contraria a los preceptos constitucionales (art. 185, Cn). Esto se conoce como control difuso de constitucionalidad. Sin embargo, el control concentrado de constitucionalidad, cuyo efecto es la expulsión de la disposición del ordenamiento jurídico, es una atribución exclusiva del juez constitucional. En este caso y de conformidad con el art. 77-E, LPC, es necesaria la certificación de la resolución en la que se declaró la inaplicabilidad. 
El proceso de inconstitucionalidad puede ser ilustrado de la siguiente manera:

Figura 6. Proceso de inconstitucionalidad

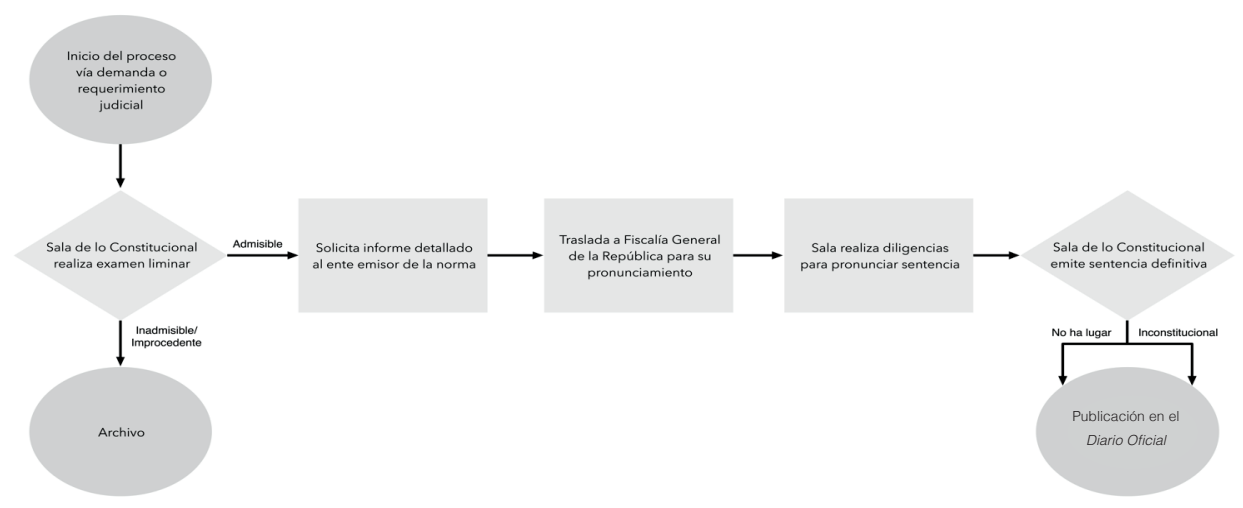

Fuente: elaboración propia, con base en la Constitución de El Salvador y la Ley de Procedimientos Constitucionales.

Casos de procesos de inconstitucionalidad que tienen incidencia sobre el Ejecutivo son, por ejemplo, el proceso acumulado 1-2010/27-2010/28-2010 de agosto del 2010, donde la Sala de lo Constitucional declaró inconstitucionales algunos artículos de la Ley de Presupuesto para el ejercicio financiero fiscal 2010. También, en el 2017, la Sala declaró inconstitucional la ley que contenía el Presupuesto General para el ejercicio financiero fiscal de ese año y emitió lineamientos para los ejercicios posteriores. Otro ejemplo es el proceso 63-2013, donde se declararon inconstitucionales artículos de la Ley del Fondo de Atención a las Víctimas de Accidentes de Tránsito (FONAT) por considerar que violaba los principios de equidad tributaria.

De igual manera, han sido objeto de control constitucional diversos decretos ejecutivos, entre los que se puede mencionar la inconstitucionalidad con referencia 8-2014, contra las "Disposiciones para regular la eficaz gestión de la Administración Pública en el marco del proselitismo electoral y de las actividades que el mismo conlleva", cuya sentencia fue emitida el 28 de febrero de 2014, declarándolas inconstitucionales por habilitar diversas formas de manifestación pública de apoyo a partidos políticos o candidatos prohibidas por la Constitución.

Dentro del funcionar de la Sala, hay ciertas dificultades que comprometen su función de órgano de control. Es sabido que un tribunal constitucional puede cambiar criterios jurisprudenciales, atendiendo a ciertos elementos. Uno de ellos es por el cambio de la configuración subjetiva del tribunal. Esto presenta problemas, ya que las y los magistrados de la Sala de lo Constitucional son elegidos por la Asamblea Legislativa. Una Asamblea que se incline hacia un espectro ideológico o partidario seleccionará candidaturas a magistrados en ese sentido, ya que, a la fecha, no existen baremos vinculantes que permitan que la Asamblea Legislativa elija con base en criterios objetivos, en función de la competencia, moralidad, honradez e independencia de los candidatos.

Ante una nueva conformación subjetiva del tribunal, pues, los criterios jurisprudenciales corren peligro, sobre todo si, como se 
menciona, la nueva integración sea de magistrados no idóneos o cercanos a una ideología o partido, comprometiendo así la independencia judicial. Elegir personas no idóneas para un cargo de este tipo es gravísimo, sobre todo por las repercusiones que tienen las sentencias en materia constitucional.

Otro tema también es la mora judicial, pero en el sentido de que en la normativa no existen criterios para dilucidar de qué forma ir avanzando en la resolución de los procesos. El juez constitucional debe tener en cuenta diversos criterios de prudencia a la hora de dictar sus resoluciones; sin embargo, es importante no dejar que los procesos se estanquen de forma exacerbada. Así, hay casos que han tardado años en pronunciarse, mientras que otros se resuelven de forma más expedita. No hay herramientas procesales en la normativa para exigir la celeridad sobre algún caso. También, por la naturaleza de los procesos, es menester que la resolución sea oportuna.

\subsection{Corte de Cuentas de la República}

La Corte de Cuentas de la República (CCR) es un órgano constitucional, independiente tanto funcional como económicamente y llamado por antonomasia a fiscalizar el erario público y el desarrollo de la actividad económico-financiera del Estado, mediante el seguimiento de la ejecución presupuestaria. Tiene por ley principal la aprobada por Decreto n. ${ }^{\circ}$ 438, del 31 de agosto de 1995, publicada en el Diario Oficial, n. ${ }^{\circ} 176$, t. 328 , del 25 de septiembre de 1995.

La Sala de lo Constitucional ha dicho en la sentencia de inconstitucionalidad 11-97, de 16 de julio de 2002, que en el "campo funcional, la independencia se manifiesta en la subordinación del órgano fiscalizador únicamente a los preceptos constitucionales que lo establecen y regulan y a los de su respectiva ley que reglamentan y complementan aquellos". Asimismo, en cuanto a la independencia económica, refiere la Sala que implica tanto "la disposición de recursos propios que le posibiliten quedar al margen de la interven- ción de otros órganos a los que debe fiscalizar en la ejecución de sus presupuestos, evitando, de esa forma, que los recursos puedan verse disminuidos con espíritu persecutorio", como "la libertad de disposición de los bienes que se le asignan sin otra limitación que los fines contenidos en la normativa que regula su funcionamiento."

Su rol de control es en extremo relevante frente al órgano ejecutivo, como máximo implementador del presupuesto general del Estado. En el art. 5 de la Ley de la Corte de Cuentas de la República (LCCR), en consonancia del art. 195, Cn, se exponen las diversas concreciones del control político sobre las distintas instituciones, pero para lo que el presente análisis respecta, sobre el órgano ejecutivo.

Sobre la función fiscalizadora, en sentencia de inconstitucionalidad 116-2017, la Sala de lo Constitucional ha expuesto que esta "estriba en el control del gasto público y la detección de desviaciones, ocultamientos, ineficiencias o malversaciones, con el objeto de ser castigadas o corregidas" y culla ejecución se realiza tanto desde la fiscalización en sentido estricto como del enjuiciamiento contable, mediante el juicio de cuentas en el ejercicio de la función jurisdiccional de la Corte de Cuentas de la República. Esta práctica de control posee un sistema estructurado de instancias y recursos que se activan ante las inconformidades de los sujetos que rinden cuentas y el fiscal general de la República en representación de los intereses del Estado y de la sociedad (art. 193, ord. 1. ${ }^{\circ}, \mathrm{Cn}$ ).

En concreto, el enjuiciamiento contable es la fase posterior a la fiscalización. El art. 15, LCCR establece que el enjuiciamiento contable tiene por objetivo establecer responsabilidades de carácter administrativo o patrimonial $y$, por ende, el reintegro de los fondos públicos utilizados indebidamente $\mathrm{o}$ dejados de percibir ante una determinación, liquidación o calificación del ingreso deficiente o ilegal. 
Según la Sala de lo Constitucional, en la sentencia de inconstitucionalidad 116-2017, tiene por finalidad conocer de los supuestos que originan la llamada "responsabilidad patrimonial", para obtener en último término el reintegro del dinero que se gastó inadecuadamente o del que no ingresó oportunamente por la deficiente o ilegal determinación administrativa, liquidación o calificación del ingreso.

Según esta misma resolución, los intervinientes en esta etapa "actúan como partes: el funcionario o persona que rinde la cuenta y el Fiscal General de la República en representación de los intereses del Estado y de la sociedad" (art. 193, ord. 1. ${ }^{\circ}, \mathrm{Cn}$.). De esto se sigue - tal como se subrayó en la sentencia de inconstitucionalidad 49-2011, citada por la inconstitucionalidad 3-2015- que "el enjuiciamiento de cuentas constituye claramente una actividad equivalente a la jurisdiccional (jurídico procesal), ejercitada por las Cámaras de Primera y Segunda Instancia de la Corte de Cuentas".

\subsubsection{Auditoría gubernamental (financiera, operacional o de gestión, examen especial, sistema informático y gestión ambiental)}

El procedimiento de la práctica de la fiscalización se encuentra desarrollado en la LCCR y en las normativas institucionales, especialmente las Normas de Auditoría Gubernamental, las Políticas de Auditoría Gubernamental y las Normas de Control Interno emitidas por la CCR.

La fiscalización que lleva a cabo la CCR, a través de los auditores designados, profesionales autorizados para su ejercicio, implica la revisión del sometimiento de la actividad económico-financiera de cada entidad a los principios de legalidad, eficiencia, racionalidad, efectividad y de máximo provecho institucional de los recursos públicos.

Para garantizar independencia del trabajo de los equipos auditores la LCCR prevé en el art. 44, inc. 2 que los auditores no podrán desplegar sus actuaciones en instituciones en los que hubieren prestado servicios dentro de los últimos cinco años, excepto en calidad de auditor interno. Tampoco sobre actividades ejecutadas por sus parientes que estén dentro del cuarto grado de consanguinidad o segundo de afinidad ni cuando existan un real o potencial conflicto de intereses.

Según el art. 30, LCCR, la auditoría gubernamental puede ser (i) financiera, si tiene por objeto el examen y evaluación de transacciones, registros, informes y estados financieros; legalidad de las transacciones y el cumplimiento de otras disposiciones; control interno financiero, y (ii) operacional, si está referida a la planificación, organización, ejecución y control interno administrativo; eficiencia, efectividad y economía en el uso de los recursos humanos, ambientales, materiales, financieros y tecnológicos, y los resultados de las operaciones y el cumplimiento de objetivos y metas. Podrán efectuarse también exámenes especiales si están referidos al análisis o revisión puntual de cualquiera de los elementos mencionados.

Para realizar el proceso de fiscalización en la etapa administrativa, la CCR está organizada en Direcciones de Auditoría, a cargo de un director, un subdirector y las jefaturas de equipo y auditores. La distribución de las entidades a fiscalizar por las distintas Unidades de Auditoría está previamente determinadas por acuerdos, que por lo general son invariables. Esto, sin bien garantiza que no intermedien criterios subjetivos en la selección de la Unidad, habría que asegurar que el personal de la unidad correspondiente varíe entre auditoría y auditoría, de lo contrario podrían crearse vínculos institucionales no deseados como contratación de familiares de los auditores.

Las direcciones de auditoría emiten las órdenes de trabajo a partir de su plan anual operativo, avalado por la CCR. En la orden de trabajo se delimitan: (a) objetivos, (b) tiempos, (c) recursos humanos, (d) designación de jefe de equipo y auditores, mientras se le notifica a la entidad auditada el inicio 
del proceso de fiscalización, requiriéndosele una reunión para la presentación del equipo auditor y efectuar las coordinaciones logísticas necesarias como el lugar físico para su instalación y las instrucciones correspondientes para la entrega irrestricta de los registros, archivos y documentos que se soliciten.

Una vez instalado el equipo de trabajo, el jefe de equipo lo comunica al director de Auditoría e inicia con los requerimientos de información necesaria in situ para proceder a la verificación de la misma y la comprobación de los procesos con base en las normas de auditoría gubernamental de CCR y las normas de control interno de cada institución.

Finalizado el proceso de levantamiento y análisis, se efectúa una comunicación con las deficiencias detectadas para que la administración las desvanezca. Posteriormente, se elabora el borrador de informe y se da lectura del mismo con las áreas objeto de auditoría o las jefaturas que intervienen en el proceso verificado, otorgándoseles un plazo para presentar explicaciones, pruebas o subsanar observaciones.

El equipo auditor revisa las pruebas y procede a redactar el informe definitivo con sus consideraciones al respecto y las recomendaciones que correspondan, las que por su carácter vinculante tendrán seguimientos posteriores. Si las observaciones son subsanadas, se emite la solvencia respectiva, de lo contrario se inicia el juicio de cuentas. El informe final de auditoría es de naturaleza pública como parte del control vertical que se pueda ejercer.

Asimismo, la CCR está facultada, a tenor del art. 46, LCCR, a remitir al superior jerárquico del órgano que corresponda, en este caso del Ejecutivo, a las "irregularidades relevantes comprobadas a cualquier funcionario o empleado público en el manejo de bienes y fondos sujetos a fiscalización". 
Figura 7. Proceso de auditoría gubernamental

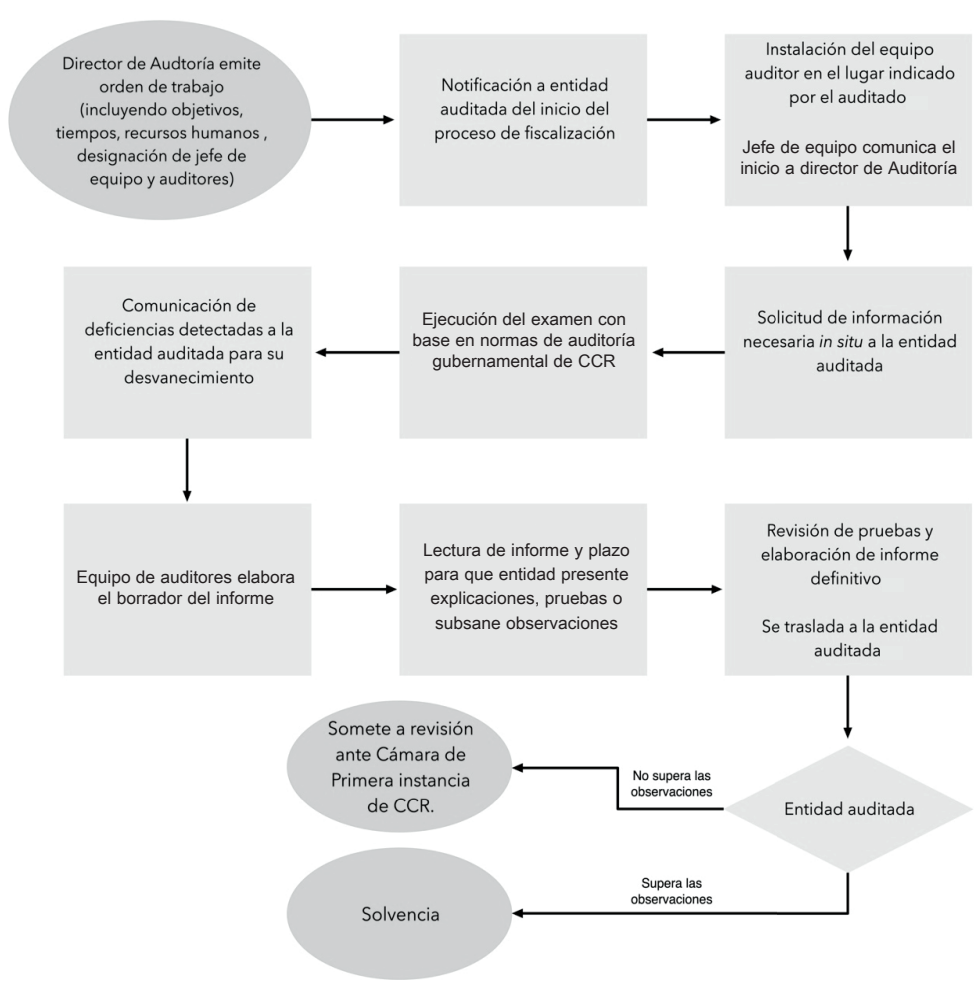

Fuente: elaboración propia con base en la Constitución y la Ley de la Corte de Cuentas de la República.

Los tipos de responsabilidad que pueden ser determinadas por la CCR como resultado del proceso de fiscalización son: a) administrativa, ante la inobservancia de la regulación y por el incumplimiento de atribuciones, facultades, funciones y deberes o estipulaciones contractuales en razón de su cargo, lo que será sancionado con multa, y b) patrimonial, determinada frente al perjuicio económico demostrado por la disminución del patrimonio de la institución ante la acción u omisión culposa de sus servidores o de terceros.

La LCCR clasifica la responsabilidad en los arts. 57, 58, 59, 60 y 61, como: a) directa, para cualquier servidor público que administre recursos financieros o tengan a su cargo el uso, registro o custodia de recursos materiales; b) principal, para quien reciba un pago con fondos públicos sin causa real o lícita, en exceso de lo que le corresponda; no liquide anticipos, préstamos o cualquier otra clase de fondos en el tiempo establecido; c) conjunta o solidaria, si existiera coautoría del mismo acto administrativo que haya generado la responsabilidad; d) subsidiaria, cuando un servidor público sea relevado de su responsabilidad legal, al haber alegado el cumplimiento de órdenes superiores con respecto al uso ilegal de inmuebles, muebles y demás bienes, salvo si al haberlo objetado conste por escrito que el superior lo haya autorizado, en cuyo caso 
este será el responsable directo por la pérdida, deterioro o daño que sufran las entidades y los organismos; e) por acción u omisión.

Emitidos los informes de autorías con responsabilidades determinadas y habiendo sido notificado si contiene hallazgos u observaciones, se remite a la Unidad de Recepción y Distribución de Informes de Auditoría de la $\mathrm{CCR}$, para que inicie el proceso jurisdiccional de cuentas, que tiene como principales falencias:

a. La inexistencia de un plazo para que la Cámara de Segunda Instancia, es decir, el pleno de los magistrados de la CCR, resuelva los recursos de apelación y revisión a las resoluciones dictadas en Primera Instancia, evitando que los magistrados tarden varios años en resolver.

b. La facultad de las Cámaras de Primera Instancia para pronunciar sentencia en juicio de cuentas caduca en dos años contados desde la fecha en la que estas reciben el informe de auditoría. Aun cuando la propia ley establece que de ser declarada la caducidad debe abrirse un expediente para deducir responsabilidades, ya sea contra los funcionarios y empleados administrativos de la CCR como sobre los jueces de las Cámaras de Primera Instancia, si fuere el caso, la sanción es solo de hasta diez veces el salario mensual del responsable, sin perjuicio de responsabilidades penales, debiendo informarse a la FGR.

A partir de solicitudes de información, se verifica que no hay registro en la CCR de procedimientos de este tipo.

c. La CCR, aun cuando está facultada por la Constitución y la ley para fiscalizar los fondos públicos independientemente del actor que los ejecute o administre, ha restringido su actuación sobre distintos actores como sindicatos de instituciones que por contrato colectivo de trabajo están obligados a asignarles recursos, o los partidos políticos cuya primera auditoría sobre el uso de la deuda política se efectuó en 2019 sobre los fondos otorgados para la elección de 2015.

d. La ley carece de mecanismos ágiles para asegurar la entrega oportuna e irrestricta a la información requerida a las instituciones auditadas por lo que es posible que a los cuerpos auditores se les limite de hecho el ejercicio de sus funciones, sin que exista un procedimiento expedito para garantizar el acceso a la información de esta institución de control, dependiendo de la actuación de la FGR para la deducción posterior de responsabilidades, haciendo el control ineficaz.

Esta práctica de control es habitualmente cuestionada por su falta de oportunidad y por el constante desvanecimiento de la responsabilidad administrativa o patrimonial de los funcionarios ante el señalamiento de los auditores. Esto puede tener por fundamento situaciones como:

a. Falta de procesos claros de contratación del personal auditor, lo que deviene en contrataciones bajo criterios políticos partidarios y familiares.

b. Cuestionada idoneidad de los responsables de equipos de trabajo, lo que evidencia una inexistente política de recursos humanos que fomente el ascenso a partir de criterios previamente establecidos, desmotivando al personal.

c. Escasa formación para el ejercicio de la función auditoria y carente especialización de la auditoría, lo que coincide con la nula evaluación del desempeño de los auditores ni del clima organizacional aun cuando estén regulados.

d. Poca cultura de los servidores públicos sobre el control interorgánico, por lo que las auditorías no son apreciados 
como un mecanismo correctos $\mathrm{o}$ disuasorio de prácticas ilegales, sino como un peligro para el ejercicio de la discrecionalidad administrativa.

e. Recarga laboral que impide un mejor desempeño en la evaluación de las muestras determinadas para auditar.

Auditar el destino de los fondos públicos es verificar que los recursos se utilicen adecuadamente para asegurar el cumplimiento de los roles que el sistema les otorga a las instituciones gubernamentales. Garantizar que auditores y auditados cumplan con sus obligaciones previene la corrupción.

\section{A modo de cierre}

Uno de los presupuestos básicos de una efectiva rendición de cuentas es contar con un marco regulatorio sistemático, íntegro, eficaz. El derecho aplicable no puede ser tan laxo que vuelva la norma inoperante o insuficiente para contrarrestar las actuaciones que se quieren evitar. Al respecto, existen prácticas de control en las que no hay una sanción. Esto implica que los A puedan presentar comportamientos eminentemente formales mas no materiales en el cumplimiento de los requerimientos, evidenciándose una deficiencia del mecanismo de $\mathrm{RdC}$; por ejemplo, ante la no aprobación de los informes anuales.

En otros casos, la práctica está sujeta a la conformación subjetiva del $\mathrm{P}$, lo que lleva a cambios de criterios, apartándose de sus precedentes, como ocurre en el caso de la Sala de lo Constitucional.

En el ámbito presupuestario, aun cuando la LRF establece sanciones ante el incumplimiento de la presentación de anexos como declaraciones juradas al Presupuesto General, estas nunca se han aplicado.

Estos vacíos son determinantes para que la rendición de cuentas funcione o no. Y un marco regulatorio deficiente o laxo, en conjunto con otros elementos que influyen en el control, hacen que este sea ineficaz.

Con todo, es importante hacer notar que la existencia de estos marcos regulatorios que desarrollan cada una de las prácticas de rendición de cuentas no asegura completamente la eficacia y la eficiencia que se esperaría de las instituciones al evaluar las políticas y los programas públicos. Hay un entramado complejo de factores que influyen en un sistema de control eficiente. Pero por eso es importante que, quienes deben llevar a cabo las prácticas, es decir, los "principales", funcionarios y empleados públicos de las instituciones de rendición de cuentas, en el ejercicio de sus competencias, deben procurar requerir los elementos necesarios para señalar las insuficiencias encontradas y su posterior sanción correspondiente.

\section{Referencias bibliográficas}

Aguilar, J. y Guevara, C. (2013). La percepción de la seguridad y la confianza en las instituciones públicas. Resultados de la segunda medición de indicadores del plan de acción asocio para el crecimiento. USAID. http://repositorio.uca.edu.sv/ jspui/bitstream/11674/756/1/percepcion \%20 IP-segunda\%20medición-2013-esp.pdf

Aguilar, J. y Andrade, L. (2016). La percepción de la seguridad y la confianza en las instituciones públicas. Tercera medición del plan de acción asocio para el crecimiento. USAID. http://repositorio.uca.edu.sv/ jspui/bitstream/11674/757/1/percepcion \%20 SIP-tercermedic-2016-esp.pdf

Aguilar, J. y Andrade, L. (2017). La percepción de la seguridad y la confianza en las instituciones públicas. Cuarta medición de indicadores del plan de acción asocio para el crecimiento. USAID. http://repositorio.uca.edu. sv/jspui/bitstream/11674/758/1/percepcion $\% 20$ IP-cuarta\%20medicion-2017-esp.pdf

Artiga-González, Á. (2015). El sistema político salvadoreño. PNUD. 
Artiga-González, Á., Benítez, J. L., Miranda Duke, A., Monterroza Marín, C. R., Rosales Martel, M. A. y Armino Martínez, L. (2008). Rendición de cuentas en el Sector Público de El Salvador. USAID.

$$
\text { Asenjo Ruiz, C. (2016). Guía }
$$
para el diseño, gestión y utilización de evaluaciones de programas y políticas públicas. Cyan, Proyectos Editoriales. http://sia.eurosocial-ii.eu/files/ docs/1460977721-DT_45_guia\%20de\%20 evaluacion(montado).p $\overline{\mathrm{d} f}$

Emmerich, G. E. (2004). Transparencia, rendición de cuentas, responsabilidad gubernamental y participación ciudadana. Polis: Investigación y Análisis Sociopolítico y Psicosocial, 2(4), 67-90. https://www.redalyc. org/pdf/726/72620404.pdf

Escobar Nolasco, M. (2005). La transparencia en el Estado salvadoreño: la perspectiva de los empresarios. Instituto Universitario de Opinión Pública (UCA).

Estella de Noriega, A. (2020). Confianza institucional en América Latina: un análisis comparado. Fundación Carolina.

Fagbadedbo, O. (2019). Introduction: Understanding the Legislature as an Instrument of Accountability. En O. Fagbadebdo \& F. Ruffin (Eds.), Perspectives on the Legislature and the Prospects of Accountability in Nigeria and South Africa (pp. 1-15). Springer Nature.

Instituto Universitario de Opinión Pública. (2011). Encuesta de evaluación del año 2010. UCA. http://www2.uca.edu.sv/publica/iudop/ Web/2010/informeval126.pdf

Instituto Universitario de Opinión Pública. (2005). Encuesta de evaluación del año 2005. UCA. http://www2.uca.edu.sv/publica/iudop/ Web/2005/informe109.pdf

Instituto Universitario de Opinión Pública. (2001). Encuesta de evaluación del año 2000. UCA. http://www2.uca.edu.sv/publica/iudop/ informes1a100/informe86.pdf
Lindberg, S. I. (2009). Accountability: Core Concept and Its Subtypes. UK Department for International Development.

O’Donnell, G. (2000). Estado de Derecho y Democracia en América Latina.

Payne, M., Zovatto, D., Carrillo, F. y Allamand, A. (2003). La política importa. IDB Bookstore.

Peixoto, T. (2013). The Uncertain Relationship between Open Data and Accountability: A Response to $\mathrm{Yu}$ and Robinson's The New Ambiguity of "Open Government". UCLA Law Review Discourse, 200, 200-213. https://www.uclalawreview.org/pdf/discourse/60-14.pdf

Pineda Pablos, N., García Figueroa, G. y Rodríguez, E. (2007). Democratización y rendición de cuentas. El caso de la revisión de las cuentas públicas municipales en Sonora. Gestión y Política Pública, XVI(1), 203-236. http://www.scielo.org.mx/pdf/gpp/ v16n1/1405-1079-gpp-16-01-203.pdf

Rodríguez Padilla, P. I. y Vega Servín, M. A. (2011). La importancia de las auditorías sobre el desempeño gubernamental en el desarrollo nacional (Trabajo presentado en Undécimo Certamen Nacional de Ensayo sobre Fiscalización Superior y Rendición de Cuentas). ASF-UNAM-CIDE.

Schedler, A. (2004). ¿Qué es la rendición de cuentas? Instituto Federal de Acceso a la Información Pública.

Velásquez Leal, L. F. e Insausti, M. B. (2014). Las entidades fiscalizadoras superiores y la rendición de cuentas. Comisión Técnica de Prácticas de Buena Gobernanza. 